\title{
Influence of betaine and arginine supplementation of reduced protein diets on fatty acid composition and gene expression in the muscle and subcutaneous adipose tissue of cross-bred pigs
}

\author{
Marta S. Madeira ${ }^{1}$, Eva A. Rolo ${ }^{1}$, Cristina M. Alfaia ${ }^{1}$, Virgínia R. Pires ${ }^{1}$, Richard Luxton ${ }^{2}$, Olena Doran ${ }^{2}$, \\ Rui J. B. Bessa ${ }^{1,3}$ and José A. M. Prates ${ }^{1 *}$ \\ ${ }^{1}$ Centro de Investigação Interdisciplinar em Sanidade Animal (CIISA), Faculdade de Medicina Veterinária, Universidade de \\ Lisboa, Avenida da Universidade Técnica, Alto da Ajuda, 1300-477 Lisboa, Portugal \\ ${ }^{2}$ Centre for Research in Biosciences, Faculty of Health and Life Sciences, University of the West of England, Coldharbour Lane, \\ Bristol BS16 1QY, UK \\ ${ }^{3}$ Unidade de Investigação em Produção Animal (UEISPA), Instituto Nacional de Investigação Agrária e Veterinária, Fonte \\ Boa, 2005-048 Vale de Santarém, Portugal
}

(Submitted 2 July 2015 - Final revision received 19 November 2015 - Accepted 7 December 2015 - First published online 28 January 2016)

\begin{abstract}
The isolated or combined effects of betaine and arginine supplementation of reduced protein diets (RPD) on fat content, fatty acid composition and mRNA levels of genes controlling lipid metabolism in pig $m$. longissimus lumborum and subcutaneous adipose tissue (SAT) were assessed. The experiment was performed on forty intact male pigs (Duroc $\times$ Large White $\times$ Landrace cross-breed) with initial and final live weights of 60 and $93 \mathrm{~kg}$, respectively. Pigs were randomly assigned to one of the following five diets ( $n$ 8): 16.0\% of crude protein (control), $13.0 \%$ of crude protein (RPD), RPD supplemented with $0.33 \%$ of betaine, RPD supplemented with $1.5 \%$ of arginine and RPD supplemented with $0.33 \%$ of betaine and $1.5 \%$ of arginine. Data confirmed that RPD increase intramuscular fat (IMF) content and total fat content in SAT. The increased total fat content in SAT was accompanied by higher GLUT type 4, lipoprotein lipase and stearoyl-CoA desaturase mRNA expression levels. In addition, the supplementation of RPD with betaine and/or arginine did not affect either IMF or total fat in SAT. However, dietary betaine supplementation slightly affected fatty acid composition in both muscle and SAT. This effect was associated with an increase of carnitine O-acetyltransferase mRNA levels in SAT but not in muscle, which suggests that betaine might be involved in the differential regulation of some key genes of lipid metabolism in pig muscle and SAT. Although the arginine-supplemented diet decreased the mRNA expression level of PPARG in muscle and SAT, it did not influence fat content or fatty acid composition in any of these pig tissues.
\end{abstract}

Key words: Betaine: Arginine: Reduced protein diets: Lipid metabolism: Intramuscular fat: Fatty acid composition: Pigs

Pork is the most consumed meat in European Union countries, with 22358000 tonnes of pig carcass produced in $2014^{(1)}$. Owing to the genetic selection towards reduced subcutaneous fat, the amount of intramuscular fat (IMF) in commercial cross-bred pigs has also been decreased ${ }^{(2)}$. It was proposed that acceptable pork eating quality requires a minimum IMF of $2 \cdot 5 \%^{(3)}$. However, according to Daszkiewicz et al. ${ }^{(4)}$ about $84 \%$ of the carcass from commercial pigs have a IMF content below the level required for acceptable eating quality. In addition, fatty acid composition plays an important role in the eating quality and nutritional value of meat. Thus, one of the main goals of the meat industry is to improve fat partitioning - namely, the production of pork with higher amounts of IMF and a balanced fatty acid composition without an increase in subcutaneous fat.

In pigs, fat partitioning can be improved by using different feeding strategies. These strategies are mainly based on the manipulation of dietary amino acid supplementation and reduction of the dietary protein content (reduced protein diets $(\mathrm{RPD}))^{(5,6)}$. Betaine, or trimethylglycine, is a metabolic product present in plant and animal tissues. Its acts as an organic osmoprotectant or as a methyl donor, which may partially reduce the requirements for other methyl donors during lipid metabolism ${ }^{(7)}$.

Abbreviations: $A C A C A$, acetyl-CoA carboxylase $\alpha$; cDNA, complementary DNA; $C P T$-1B, carnitine palmitoyltransferase 1B; $C R A T$, carnitine $O$-acetyltransferase; $F A B P 4$, fatty acid binding protein 4, adipocyte; FADS1, fatty acid desaturase $1 ; F A D S 2$, fatty acid desaturase 2 ; FAME, fatty acid methyl esters; FASN, fatty acid synthase; GLUT4, solute carrier family 2, facilitated GLUT member 4; IMF, intramuscular fat; $L P L$, lipoprotein lipase; MLXIPL, MLX interacting protein-like; RPA, reduced protein diet with arginine; RPB, reduced protein diet with betaine; RPBA, reduction protein diet with betaine and arginine; RPD, reduced protein diets; RPLP0, ribosomal protein large P0; SAT, subcutaneous adipose tissue; SCD, stearoyl-CoA desaturase.

*Corresponding author: J. A. M. Prates, fax +351 213652 895, email japrates@fmv.ulisboa.pt 
In fact, dietary betaine supplementation may decrease the requirements for other methyl donors such as methionine and choline $^{(8)}$. It has been demonstrated that dietary betaine supplementation in pigs may repress overall fat deposition ${ }^{(9)}$. As reported by Huang et $a l .^{(9,10)}$, the addition of betaine to the diet of growing-finishing pigs results in decreased carcass fat deposition by increasing the rate of lipolysis and/or decreasing the rate of lipogenesis. Moreover, arginine is a semi-essential amino acid that, in addition to playing multiple physiological functions in animals, enhances lipolysis through the expression of key genes responsible for the activation of fatty acid oxidation in a tissue-specific manner ${ }^{(11,12)}$. Previous studies have suggested that dietary arginine supplementation to growing-finishing pigs increased the IMF content, and thus improved fat partitioning ${ }^{(12,13)}$. However, we have recently showed that dietary arginine supplementation, either alone or in combination with RPD, does not increase IMF content or change the fatty acid composition in pigs $^{(14)}$. In addition to the use of dietary amino acid supplementation, the use of RPD for increasing IMF content in pigs with less effect on subcutaneous fat deposition has also been reported ${ }^{(5,15)}$. Although the mechanisms of the tissuespecific effects of RPD are not clear ${ }^{(5)}$, one possibility might be a dietary-stimulated increase in stearoyl-CoA desaturase (SCD) activity in pig muscle but not in subcutaneous adipose tissue $(\mathrm{SAT})^{(5)}$. Moreover, recent results from our research group ${ }^{(15)}$ showed the existence of breed-specific effects of fat deposition promoted by RPD in pigs, with increased IMF content in lean pig genotypes but not in fat ones.

The main site for de novo fatty acid biosynthesis and lipogenesis in pig is the white adipose tissue ${ }^{(16)}$. In contrast, muscle is one of the tissues playing the main role in the metabolism of glucose and degradation of lipids ${ }^{(17)}$. The mechanisms that regulate adipogenesis and lipogenesis are controlled by a range of key transcription factors including sterol regulatory element binding protein 1 (SREBP1), CCAAT/enhancer binding protein $\alpha$ (CEBPA) and PPARG ${ }^{(18)}$. In addition, MLX interacting proteinlike (MLXIPL) is a critical glucose-responsive transcription factor that regulates lipogenic and glycolytic genes, highly controlled by the insulin-regulated solute carrier family 2 , facilitated GLUT member 4 (GLUT4) in adipose tissue ${ }^{(19)}$. Furthermore, the MLXIPL also regulates various enzymes involved in glycolysis and lipogenesis, such as acetyl-CoA carboxylase (ACACA) and fatty acid synthase $(\mathrm{FASN})^{(20)}$. $\mathrm{ACACA}^{(21)}$ and $\mathrm{FASN}^{(22)}$ are the lipogenic enzymes controlling the rates of SFA biosynthesis, and SCD catalyses the rate-limiting step of MUFA biosynthesis. Fatty acid desaturase 1 (FADS1) and desaturase 2 (FADS2) genes encode for $\Delta 5$ and $\Delta 6$ desaturases, respectively, which are membrane-bound enzymes that catalyse the synthesis of PUFA $^{(23)}$. Moreover, carnitine palmitoyltransferase 1B (CPT-1B) and carnitine $O$-acetyltransferase (CRAT) are the rate-limiting enzymes of lipid catabolism and are responsible for the transport of fatty acid esters from the cytosol to the mitochondria for $\beta$-oxidation ${ }^{(18)}$. PPARA is involved in fatty acid oxidation by upregulating the expressions of acyl-CoA oxidase and carnitine palmitoyltransferase enzymes ${ }^{(24)}$. Lipoprotein lipase (LPL) is the rate-limiting enzyme in the conversion of chylomicrons and VLDL into chylomicron remnants and LDL in tissues. Therefore, LPL controls TAG partitioning between adipose tissue and muscle, thereby increasing fattening or providing energy in the form of fatty acids for muscle growth ${ }^{(25)}$. Finally, fatty acid binding protein 4 (FABP4) is responsible for fatty acid transport in the adipocytes ${ }^{(26)}$. It remains unclear whether and how these processes contribute to the mechanisms controlling dietary regulation of fat partitioning in pigs.

We have recently shown that adipogenesis and lipogenesis are regulated differently in the muscle and SAT of commercial cross-bred pigs ${ }^{(14)}$. In addition, it was suggested that increased IMF promoted by RPD is due to lysine restriction, and it is mediated by the up-regulation of both the adipogenic transcription factor PPARG and the lipogenic enzyme SCD. Moreover, the supplementation of RPD with leucine seems to be interesting to increase MUFA content in pork ${ }^{(14)}$. Thus, in order to assess the influence of new feeding strategies, we tested the following hypotheses: (1) RPD supplemented with betaine, arginine or both improve fat partitioning and fatty acid composition in commercial cross-bred pigs; and (2) the tissuespecific effect of betaine and/or arginine supplementation of RPD is mediated via the expressions of key genes controlling lipid metabolism. The general aim of this study was, therefore, to assess whether the increased IMF content induced by RPD in the growing-finishing phase of commercial cross-bred pigs could be modulated by dietary supplementation of betaine and arginine, or both (to assess additive/interactive effects), without major undesirable increases in SAT.

\section{Methods}

\section{Animals and diets}

The trial was conducted at the facilities of Unidade de Investigação em Produção Animal (Instituto Nacional de Investigação Agrária e Veterinária (UEISPA-INIAV)), and all the experimental procedures involving animals were reviewed by the Ethics Commission of the Centro de Investigação Interdisciplinar em Sanidade Animal/Faculdade de Medicina Veterinária and approved by the Animal Care Committee of the National Veterinary Authority (Direcção-Geral de Alimentação e Veterinária), following the appropriated European Union guidelines (2010/63/EU Directive). All the staff members involved in animal trials had licence for conducting experiments on live animals from the Portuguese Veterinary Services.

In all, forty commercial cross-bred (50\% Duroc, 25\% Large White and $25 \%$ Landrace) entire male pigs with an initial body weight of 59.9 (SD 1.65) kg were used. Animals were fed a standard commercial concentrate diet from weaning until the beginning of the experiment. The forty animals were randomly allocated to ten pens and the five dietary treatments were randomly allocated to each animal, according to an incomplete balanced block design. The five diets were isoenergetically formulated (13.3 MJ metabolisable energy/ $\mathrm{kg}$ ) and differed in crude protein, betaine and arginine contents as follows: $16 \cdot 0 \%$ of crude protein (normal protein diet, control); $13.0 \%$ of crude protein (reduced protein diet, RP); $13.0 \%$ of crude protein with $0.33 \%$ betaine supplementation (reduced protein diet with betaine, RPB), $13.0 \%$ of crude protein with $1.5 \%$ arginine supplementation (reduced protein diet with arginine, RPA) and 
$13.0 \%$ of crude protein with $0.33 \%$ betaine and $1.5 \%$ arginine supplementation (reduction protein diet with betaine and arginine, RPBA). The amino acids were obtained from $\mathrm{Fh}$ Diedrichs \& Ludwig Post. The ingredients, chemical composition and fatty acid profile of the experimental diets are shown in Table 1. During the experiment, the animals were fed individually twice a day and had access to water ad libitum. Feed offered and refusals were recorded daily in order to calculate feed intake. Pigs were weighed weekly, just before feeding, throughout the experiment.

\section{Slaughter and sampling}

Feed was removed $17-19 \mathrm{~h}$ before the animals were slaughtered. Pigs were slaughtered at an average live body weight of 92.7 (SD 2.54$) \mathrm{kg}$, with no significant differences $(P>0.05)$ between animal groups, at the UEISPA Experimental Abattoir. Immediately after electrical stunning and exsanguination, samples of m. longissimus lumborum and SAT were collected from the right side of the carcass at the first lumbar vertebra level for gene expression analysis. The samples were rinsed with sterile RNAsefree cold saline solution, cut into small pieces (approximately $0 \cdot 3-\mathrm{cm}$ thick), stabilised in RNA Later solution (Qiagen) and stored at $-80^{\circ} \mathrm{C}$ until analysed. For analysis of IMF and fatty acid composition, $m$. longissimus lumborum and SAT samples were collected after slaughter from the right carcass side between the third and fifth lumbar vertebrae. Muscle samples were collected and trimmed of visible connective and adipose tissues before being blended in a food processor. The samples of muscle and SAT were vacuum packed and stored at $-20^{\circ} \mathrm{C}$ until analysed. Backfat thickness was measured in left carcass side, at the $\mathrm{P}_{2}$ (last rib position) location, using a Vernier calliper (Bochem Lab Supply).

\section{Feed analysis}

Feed samples, collected five times during the trial (the first collection was in the beginning of the trial, followed by regular collections with a 3-week interval until the slaughter) were analysed for DM by drying a sample at $100^{\circ} \mathrm{C}$ to a constant weight. $\mathrm{N}$ content was determined by the Kjeldahl method ${ }^{(27)}$, and crude protein was calculated as $6 \cdot 25 \times \mathrm{N}$. Crude fibre was determined by the procedure described by the Association of Official Analytical Chemists (AOAC) ${ }^{(27)}$. The samples were extracted with petroleum diethyl ether, using an automatic Soxhlet extractor (Gerhardt Analytical Systems), and crude fat was determined. Analysis of ash and starch contents was carried out according to the procedures described by the $\mathrm{AOAC}^{(27)}$ and Clegg $^{(28)}$, respectively. Gross energy in the feed was determined by adiabatic bomb calorimetry (Parr 1261; Parr Instrument Company). Fatty acid methyl esters (FAME) of the feed samples were analysed by one-step extraction and transesterification, using heptadecanoic acid $(17: 0)$ as the internal standard $^{(29)}$. Total amino acids were extracted from feed according to the method described by the $\mathrm{AOAC}^{(30)}$. The extract was analysed by HPLC (Agilent 1100; Agilent Technologies) to quantify total amino acids in the feed, following the procedure described by Henderson et al. ${ }^{(31)}$.

\section{Intramuscular fat and fatty acid composition}

The $m$. longissimus lumborum and SAT samples were lyophilised $\left(-60^{\circ} \mathrm{C}\right.$ and $\left.2 \cdot 0 \mathrm{hPa}\right)$ to constant weight using a lyophilisator (Edwards High Vacuum International), maintained dry at $-20^{\circ} \mathrm{C}$

Table 1. Ingredients and chemical, amino acid and fatty acid compositions of the experimental diets

\begin{tabular}{|c|c|c|c|c|c|}
\hline & Control & $\mathrm{RP}$ & RPB & RPA & RPBA \\
\hline \multicolumn{6}{|l|}{ Ingredients (\%) } \\
\hline Maize & $55 \cdot 0$ & $55 \cdot 0$ & $55 \cdot 0$ & $55 \cdot 0$ & $55 \cdot 0$ \\
\hline Soyabean meal & $19 \cdot 0$ & $10 \cdot 7$ & 11.4 & 3.90 & 4.05 \\
\hline Barley & $10 \cdot 0$ & $15 \cdot 9$ & $16 \cdot 0$ & $25 \cdot 5$ & 24.9 \\
\hline Wheat & 6.92 & $10 \cdot 0$ & $10 \cdot 0$ & $10 \cdot 0$ & $10 \cdot 0$ \\
\hline Sunflower meal & $5 \cdot 27$ & 4.79 & 3.65 & - & - \\
\hline Soyabean oil & 0.95 & 0.94 & 0.94 & 1.01 & 1.16 \\
\hline Calcium carbonate & 0.89 & 0.89 & 0.89 & 0.90 & 0.90 \\
\hline Bicalcium phosphate & 0.49 & 0.58 & 0.58 & 0.70 & 0.70 \\
\hline Salt & 0.40 & 0.40 & 0.35 & 0.39 & 0.41 \\
\hline Vitamin-trace mineral premix & 0.40 & 0.40 & 0.40 & 0.40 & 0.40 \\
\hline Mould inhibitor mixture & 0.10 & 0.10 & 0.10 & $0 \cdot 10$ & 0.10 \\
\hline Fermentation products & $0 \cdot 10$ & $0 \cdot 10$ & 0.10 & $0 \cdot 10$ & 0.10 \\
\hline Phytase mixture & $0 \cdot 10$ & $0 \cdot 10$ & 0.10 & $0 \cdot 10$ & $0 \cdot 10$ \\
\hline Acid mixture & 0.05 & 0.05 & 0.05 & 0.05 & 0.05 \\
\hline Antioxidant mixture & 0.01 & 0.01 & 0.01 & 0.01 & 0.01 \\
\hline Sodium bicarbonate & - & - & 0.08 & 0.02 & - \\
\hline L-Lys & 0.25 & 0.07 & 0.06 & 0.27 & 0.27 \\
\hline L-Thr & 0.04 & - & - & 0.05 & 0.05 \\
\hline DL-Met & 0.02 & - & - & - & - \\
\hline L-Trp & - & - & _- & 0.01 & 0.01 \\
\hline Betaine $\mathrm{HCl}$ & - & - & 0.33 & - & 0.33 \\
\hline L-Arg & - & - & - & 1.50 & 1.50 \\
\hline \multicolumn{6}{|l|}{ Chemical composition (\% diet) } \\
\hline DM & 88.5 & 88.5 & 88.6 & 88.8 & 88.7 \\
\hline Crude protein & $16 \cdot 1$ & $13 \cdot 1$ & 13.0 & $12 \cdot 8$ & 13.0 \\
\hline Starch & $45 \cdot 0$ & $49 \cdot 3$ & $48 \cdot 4$ & 47.6 & 49.9 \\
\hline Crude fat & $3 \cdot 17$ & 3.35 & 3.35 & 3.85 & 3.97 \\
\hline Crude fibre & 4.20 & 3.93 & 4.12 & $2 \cdot 60$ & $2 \cdot 77$ \\
\hline Ash & 4.21 & 3.85 & 3.64 & 3.60 & 3.64 \\
\hline $\mathrm{Ca}$ & 0.77 & 0.61 & 0.70 & 0.73 & 0.67 \\
\hline $\mathrm{P}$ & 0.42 & 0.40 & 0.41 & 0.41 & 0.39 \\
\hline ME (MJ ME/kg) & $13 \cdot 3$ & $13 \cdot 6$ & $13 \cdot 3$ & $13 \cdot 2$ & $13 \cdot 2$ \\
\hline \multicolumn{6}{|l|}{ Amino acid composition (\% diet) } \\
\hline Ala & 0.39 & 0.36 & 0.35 & 0.28 & 0.28 \\
\hline $\operatorname{Arg}$ & 0.53 & 0.39 & 0.44 & 1.05 & 1.15 \\
\hline Asp & 0.68 & 0.43 & 0.52 & 0.35 & 0.34 \\
\hline Glu & 1.17 & 0.89 & 1.01 & 0.81 & 0.79 \\
\hline Gly & 0.32 & 0.37 & 0.27 & 0.20 & 0.20 \\
\hline His & 0.23 & 0.15 & 0.21 & $0 \cdot 16$ & 0.17 \\
\hline Ile & 0.26 & 0.17 & 0.24 & 0.17 & 0.17 \\
\hline Leu & 0.64 & 0.56 & 0.56 & 0.45 & 0.45 \\
\hline Lys & 0.51 & 0.35 & 0.35 & 0.30 & 0.33 \\
\hline Met & 0.04 & 0.01 & 0.02 & 0.03 & 0.02 \\
\hline Phe & 0.33 & 0.23 & 0.28 & 0.21 & 0.21 \\
\hline Pro & 0.65 & 0.61 & 0.59 & 0.55 & 0.53 \\
\hline Ser & 0.36 & 0.32 & 0.28 & 0.21 & 0.21 \\
\hline Thr & 0.22 & 0.14 & 0.17 & 0.15 & 0.15 \\
\hline Tyr & 0.24 & 0.15 & 0.19 & 0.15 & 0.14 \\
\hline Val & 0.26 & $0 \cdot 18$ & 0.25 & 0.20 & 0.21 \\
\hline \multicolumn{6}{|l|}{$\begin{array}{l}\text { Fatty acid composition (\% total fatty } \\
\text { acids) }\end{array}$} \\
\hline $16: 0$ & $20 \cdot 4$ & $16 \cdot 1$ & $15 \cdot 5$ & 14.2 & $14 \cdot 1$ \\
\hline $18: 0$ & 4.52 & 3.27 & 3.22 & 2.77 & 2.79 \\
\hline $18: 1 c 9$ & 32.4 & 28.5 & $27 \cdot 9$ & $26 \cdot 2$ & $26 \cdot 1$ \\
\hline $18: 1 c 11$ & 1.21 & 1.03 & 0.99 & 0.91 & 0.92 \\
\hline $18: 2 n-6$ & 39.4 & $48 \cdot 3$ & 49.4 & $52 \cdot 7$ & $52 \cdot 7$ \\
\hline $18: 3 n-3$ & 2.04 & 2.75 & 2.88 & 3.24 & 3.27 \\
\hline
\end{tabular}

Control, normal protein diet; RP, reduced protein diet; RPB, reduced protein diet with betaine addition; RPA, reduced protein diet with arginine addition; RPBA, reduced protein diet with betaine and arginine addition; ME, metabolisable energy. 
and analysed within 2 weeks. The total fat content of the muscle samples (IMF) and SAT was determined using fresh samples by hydrolysis with $4 \mathrm{~m}-\mathrm{HCl}$, followed by Soxhlet extraction for $6 \mathrm{~h}$ with petroleum diethyl ether ${ }^{(27)}$. For fatty acid analysis of $m$. longissimus lumborum and SAT samples, FAME were extracted from the lyophilised samples (approximately 250 and $50 \mathrm{mg}$, respectively), according to the method described by Folch et $a l .{ }^{(32)}$, using dichloromethane-methanol $(2: 1, \mathrm{v} / \mathrm{v})$ instead of chloroform-methanol $(2: 1, \mathrm{v} / \mathrm{v})$, as described by Carlson ${ }^{(33)}$. All the extraction solvents contained $0.01 \%$ butylated hydroxytoluene as an antioxidant. Fatty acids were converted to methyl esters by a combined transesterification procedure with $\mathrm{NaOH}$ in anhydrous methanol $(0.5 \mathrm{M})$, followed by $\mathrm{HCl}-$ methanol $(1: 1, \mathrm{v} / \mathrm{v})$, at $50^{\circ} \mathrm{C}$ for 30 and $10 \mathrm{~min}$, respectively, as described by Raes et al. ${ }^{(34)}$

Quantification of FAME in muscle and SAT was performed using a GC HP7890A (Hewlett-Packard), equipped with a flame ionisation detector and a Supelcowax ${ }^{\mathrm{TM}} 10$ capillary column ( $30 \mathrm{~m} \times 0 \cdot 20 \mathrm{~mm}$ i.d., $0 \cdot 20-\mu \mathrm{m}$ film thickness; Supelco). The column temperature of $150^{\circ} \mathrm{C}$ was held for $11 \mathrm{~min}$, then increased to $210^{\circ} \mathrm{C}$ at a rate of $3^{\circ} \mathrm{C} / \mathrm{min}$ and maintained for $30 \mathrm{~min}$. He was used as the carrier gas at a flow rate of $1.3 \mathrm{ml} / \mathrm{min}$, the split ratio was $1: 20$ and $1 \mu \mathrm{l}$ of the sample was injected. The injector and detector temperatures were 250 and $280^{\circ} \mathrm{C}$, respectively. The quantification of total FAME was carried out using nonadecanoic acid (19:0) as the internal standard. Results for each fatty acid were expressed as a percentage of the sum of detected fatty acids (\% total fatty acids).

\section{RNA isolation and complementary DNA synthesis}

Total RNA from $m$. longissimus lumborum and SAT samples was isolated using QIAzol ${ }^{\circledR}$ Lysis Reagent (Qiagen) and purified with RNeasy ${ }^{\circledR}$ Lipid Mini Kit (Qiagen). All the procedures were performed in accordance with the manufacturer's protocols, and all RNA were subjected to an on-column DNAse I (Qiagen) treatment to remove any contamination with genomic DNA. RNA concentration was determined by analysis of absorbance at $260 \mathrm{~nm}$ using a NanoDrop ND-2000c spectrophotometer (Nanodrop; Thermo Fisher Scientific). The A260/280 ratios were between 1.9 and $2 \cdot 1$, and RNA integrity was evaluated by electrophoresis using $1.5 \%$ agarose gel and ethidium bromide staining $(1.25 \mathrm{ng} / \mu \mathrm{l}$; Sigma-Aldrich); $750 \mathrm{ng}$ of total RNA was reversed-transcribed using the High-Capacity cDNA Reverse Transcription Kit (Applied Biosystems), based on the use of both oligodT and random hexamers as primers, following the manufacturer's protocol as was previously described by Madeira et $a l .{ }^{(14)}$. Control reactions were carried out in the absence of RT in order to check for DNA contamination. Complementary DNA (cDNA) quality was tested by end-point PCR, amplifying all the housekeeping and target genes used in this study. The obtained cDNA was divided into aliquots and stored at $-20^{\circ} \mathrm{C}$ until further analysis.

\section{Real-time quantitative $P C R$}

Genes used in the present study were selected based on their role in the transcriptional control of adipogenesis regulation/differentiation ( $M L X I P L, P P A R G, S R E B P 1, C E B P A)$, regulation of lipogenesis ( $A C A C A, F A S N, F A D S 1, F A D S 2, S C D$ ), glucose uptake (GLUT4), fatty acid uptake $(L P L)$ and lipid oxidation (CRAT, CPT-1B, PPARA) (Table 2). Gene-specific intron-spanning primers were designed with the aid of Primer3 (http://frodo/wi.mit.edu/primer3/) and Primer Express ${ }^{\circledR} 2.0$ software (Applied Biosystems), based on Sus scrofa sequences (www.ncbi.nlm.nih.gov), to generate amplicons ranging in size from 71 to $145 \mathrm{bp}$. Sequences of primers, GenBank accession numbers, amplicon length and span exons for PCR products are provided in Table 2 . Primers were synthesised commercially by NZYTech. Sequence homology searches against the database of GenBank showed that these primers were specific to the sequence to which they were designed. In order to test the primers and verify the amplified products, a conventional PCR was carried out for all the genes investigated in this study before performing the real-time quantitative PCR experiments. In brief, genes were amplified by conventional qualitative PCR (using $1 \mu \mathrm{l}$ of cDNA) with the same primers that were designed for real-time PCR. PCR products were extracted from gels using QIAquick $^{\circledR}$ Gel Extraction Kits (Qiagen). The fragments were then cloned into the $\mathrm{pGEM}^{\circledR}$-Teasy cloning vector (Promega), transformed into pMOS Blue Escherichia coli and selected on Luria-Bertani (LB) agar plates containing ampicillin $(50 \mu \mathrm{g} / \mathrm{ml})$. Plasmids containing inserts of the right size were sequenced by Stab Vida, and homology searches were performed using Blast (www.ncbi.nlm.nih.gov/blast) to confirm the identity of the amplified fragments. The PCR efficiency was calculated for each amplicon, in triplicate, using StepOnePlus ${ }^{\mathrm{TM}}$ PCR System software (Applied Biosystems), by amplifying 5-fold serial dilutions of pooled cDNA. All primer sets exhibited an efficiency ranging between 90 and $110 \%$, and the correlation coefficients were higher than 0.99 .

The gene expression profiles of the five candidate references genes (glyceraldehyde-3-phosphate dehydrogenase, 60S ribosomal protein L27 (RPL27), ornithine decarboxylase antizyme 1, ribosomal protein large P0 (RPLPO) and $40 \mathrm{~S}$ ribosomal protein S29 (RPS29)) were analysed in twenty-four randomly selected different samples (four pigs from each group). The geNorm algorithm $^{(35)}$ and NormFinder algorithm ${ }^{(36)}$ were used to evaluate their stability in all the samples. RPLPO and RPS29 were identified as the most stable pair of endogenous control genes for normalisation of results in the $m$. longissimus lumborum, whereas RPLPO and RPL27 genes were identified as the most stable pair for SAT. Quantitative real-time PCR reactions were carried out using MicroAmp ${ }^{\circledR}$ Optical 96-well plates (Applied Biosystems) in a StepOnePlus ${ }^{\mathrm{TM}}$ thermocycler (Applied Biosystems) in standard cycling conditions. Measurements of each sample for each gene were conducted in duplicate; $12.5 \mu \mathrm{l}$ of PCR reaction mixtures contained $6.25 \mu \mathrm{l}$ of $2 \times$ Power SYBR $^{\circledR}$ Green PCR Master Mix (Applied Biosystems), $160 \mathrm{~nm}$ of gene-specific forward and reverse primers and $1.5 \mu \mathrm{l}$ of diluted cDNA as a template. Controls included no template cDNA to monitor contamination and primer dimer formation and a minus RT sample to check for genomic DNA contamination. A melting curve analysis was performed after the final cycle to ensure specificity of primer and absence of primer dimer formation. The relative amount of each target gene was 
Betaine, arginine and protein effects in pig

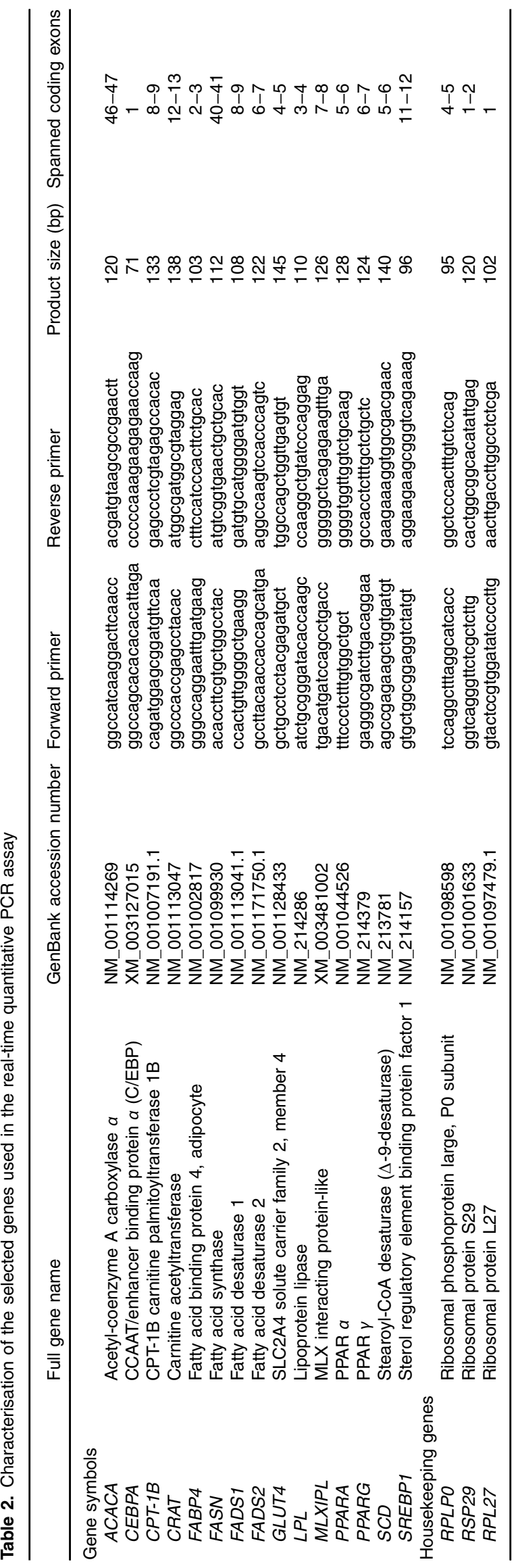

calculated using the geometric mean of RPLPO/RPS29 and $R P L P O / R P L 27$ as a normaliser for muscle and SAT, respectively. The relative gene expression levels were calculated using the Livak method $^{(37)}$, corrected for variation in amplification efficiency, as described by Fleige et al. ${ }^{(38)}$

\section{Statistical analysis}

All the data were checked for normal distribution (Shapiro-Wilk test) and variance homogeneity ( $\chi^{2}$ test). As variance heterogeneity was detected for most fatty acids and genes, these data were analysed using Proc MIXED of SAS software package ${ }^{(39)}$ (version 9.2; SAS Institute). The model included the effect of dietary protein reduction (PR), betaine and Arg. The contrast among diet types was performed as follows: $\mathrm{PR}=$ control $v$. (RP, $\mathrm{RPB}, \mathrm{RPA}, \mathrm{RPBA}) / 4$; Bet $=\mathrm{RP} v . \mathrm{RPB} ; \mathrm{Arg}=\mathrm{RP} v . \mathrm{RPA} ; \mathrm{Bet}+$ $\operatorname{Arg}=\mathrm{RP} v$. RPBA; Bet $\times \operatorname{Arg}=\mathrm{RPBA} v .(\mathrm{RPB}+\mathrm{RPA}) / 2)$. The contrast Bet $\times$ Arg enables to assess additive or interactive effects between dietary betaine and arginine supplementation of RP. Pearson's correlation matrices were computed using the PROC CORR of SAS.

\section{Results}

This study presents and discusses the results of a trial in commercial pigs aiming to investigate the dietary modulation of fat content and fatty acid composition in the $m$. longissimus lumborum and SAT. Furthermore, the possible molecular mechanisms underlying fat deposition in muscle and SAT were elucidated through the assessment of mRNA expression levels of genes encoding key lipogenic transcription factors and enzymes. This animal trial also generated results on pigs' performance, carcass traits and sensory quality of meat that are presented elsewhere ${ }^{(40)}$. In brief, the results confirmed that dietary PR enhances pork eating quality but negatively affects pigs' growth performance. Moreover, it was suggested that betaine and/or arginine supplementation of RPD does not further increase IMF content but improves some pork sensory traits, including overall acceptability.

\section{Intramuscular fat and fatty acid composition of muscle}

The results of IMF content, fatty acid composition and partial sums of fatty acids in the $m$. longissimus lumborum of crossbred pigs are presented in Table 3. The IMF content was increased by $25 \%$ for reduced protein diets (RP, RPA, RPB and RPBA groups; $P=0.041$ ) relative to the normal protein diet (control group). However, IMF content was not affected by the supplementation of reduced protein diet (RP) by betaine (RPB; $P=0.730$ ), arginine (RPA; $P=0 \cdot 344$ ) or both (RPBA; $P=0 \cdot 610$ ).

The predominant fatty acids in IMF were 18 : 1 cis-9 $(33-35 \%$ of total FAME), 16:0 (22-23\%), 18:0 (12-14\%) and 18:2n-6 (11-12\%) for all the experimental groups. The term 'others' in Table 3 refers to unidentified minor fatty acids and to the $16: 0$, 18:0 and 18:1 plasmalogen-derived dimethyl acetals. Dietary PR (RP, RPA, RPB and RPBA) resulted only in a decrease of the percentage of $16: 1$ cis-7 $(P<0.001)$, when compared with the control diet, out of the twenty-four fatty acids identified in 


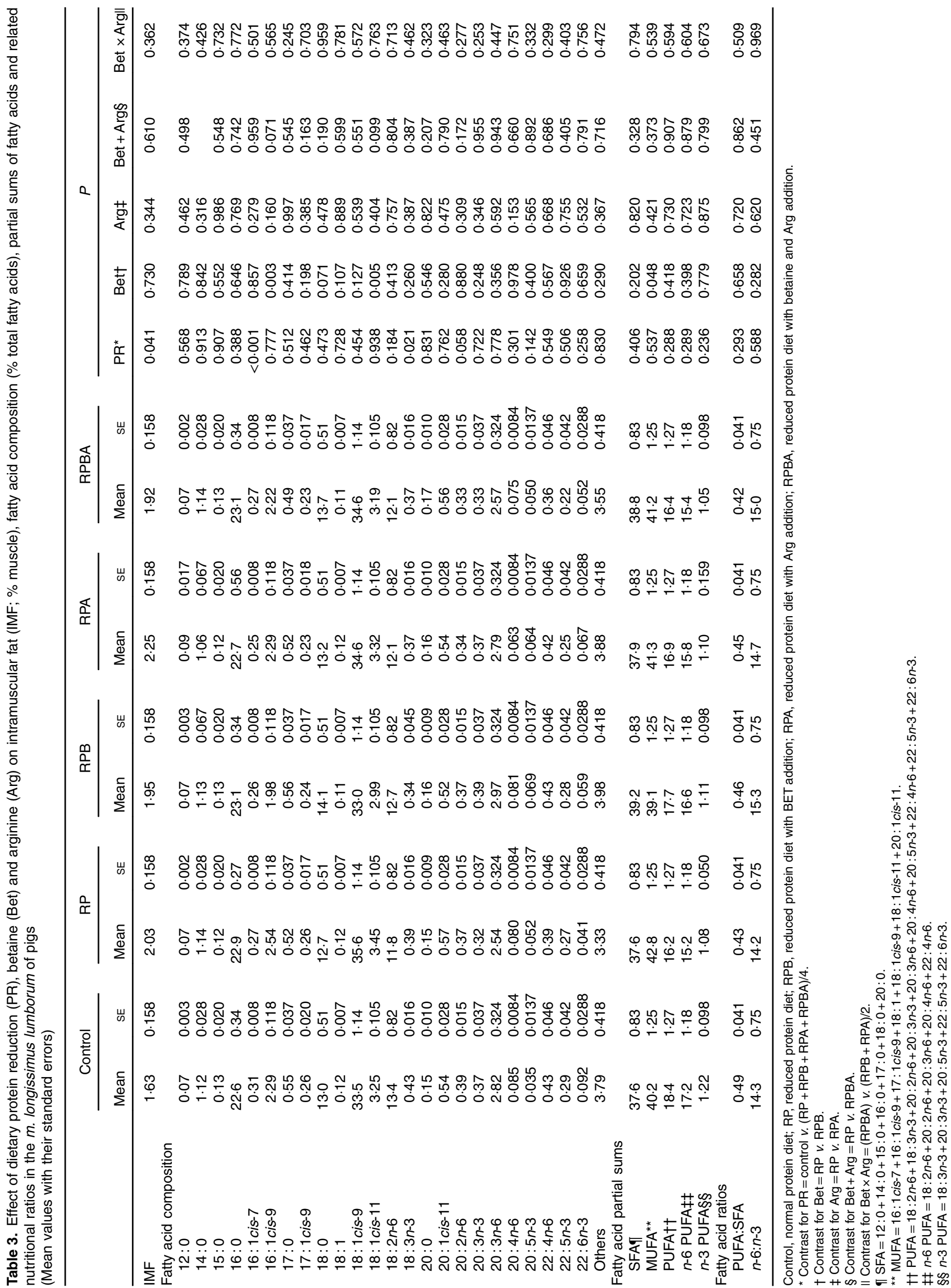


the muscle. Pigs fed the RPB had lower proportions of $16: 1$ cis-9 $(P=0.003)$ and $18: 1$ cis-11 $(P=0.005)$ than those fed the reduced protein diet $(\mathrm{RP})$. Arginine supplementation of the reduced protein diet (RPA) had no effect on fatty acid profile relative to the reduced protein diet.

Concerning the partial sums of fatty acids (Table 3), only betaine supplementation of the reduced protein diet decreased the percentage of MUFA $(P=0 \cdot 048)$, when compared with the reduced protein diet without amino acid supplementation (RP). Finally, PUFA:SFA and $n-6: n-3$ ratios, which are commonly used indices to assess the nutritional value of fatty acids, were not affected by any of the experimental treatments.

\section{Fatty acid content and composition of subcutaneous adipose tissue}

The results of backfat thickness at the $\mathrm{P}_{2}$ site, total fat and fatty acid composition for SAT are presented in Table 4. Dietary betaine, arginine and betaine plus arginine supplementation did not affect backfat thickness at the $\mathrm{P}_{2}$ site or total fat content. However, a $7 \%$ increase in total fat content was observed for pigs fed the reduced protein diets $(P=0.046)$ when compared with those fed the control diet.

The major fatty acids in SAT were 18: 1cis-9 (34-35\% of total FAME), $16: 0$ (23-24\%), 18:0 (16-18\%) and 18:2n-6 (14-16\%) across experimental groups. A reduction in the level of dietary protein (RP) resulted in a decrease of the percentages of 16:1cis-7 $(P=0.001)$ and $18: 1$ cis-11 $(P=0.035)$ when compared with the control diet. Betaine supplementation of the reduced protein diet decreased the percentages of $16: 1 \mathrm{cis}-9$ $(P=0.020)$ and $18: 1$ cis-11 $(P=0.013)$. Neither arginine nor the combination of betaine and arginine affected the fatty acid profile in SAT.

The partial sums of fatty acids (Table 4) were not affected by any experimental treatment. However, PUFA:SFA ratio was decreased under the reduced protein diet $(P=0.043)$ when compared with the control diet. In contrast, pigs fed the reduced protein diet supplemented with betaine had a higher $n-6: n-3$ ratio $(P=0 \cdot 048)$ when compared with those fed the reduced protein diet

\section{Gene expression levels in muscle and subcutaneous} adipose tissue

Expression analysis of genes controlling lipid metabolism was carried out in order to elucidate whether the tissue-specific effects of dietary protein level, betaine and arginine are associated with differential modulation of gene expression. Fig. 1 and 2 show the expression levels of fourteen key genes associated with lipid metabolism in the $m$. longissimus lumborum and SAT of pigs, respectively.

In the $m$. longissimus lumborum, the relative expression levels of two out of the fourteen genes analysed were affected by, at least, one dietary treatment. The expression level of the PPARA gene was lower $(P=0.027)$ in pigs fed the reduced protein diet (RP) when compared with that fed the normal protein diet (control diet). In addition, both arginine $(P=0.022)$ and betaine plus arginine $(P=0.025)$ supplementation of the reduced protein diet decreased the mRNA level of the PPARG gene.

In SAT, the mRNA levels of six out of the fourteen genes analysed were affected by one dietary treatment. The expression levels of GLUT4 $(P=0.026), L P L(P=0.015)$ and $S C D$ $(P=0.023)$ genes were up-regulated in pigs fed the reduced protein diet when compared with those fed the control diet. Dietary betaine supplementation of the reduced protein diet decreased the CRAT mRNA level $(P=0.004)$, whereas dietary arginine supplementation decreased the PPARG expression level $(P=0 \cdot 045)$. Finally, dietary betaine plus arginine supplementation increased the FADS2 expression level $(P=0.028)$ when compared with the diets with either betaine or arginine supplementation.

\section{Correlation between fatty acid composition and gene expression levels}

The correlation coefficients $(r)$ between fatty acid composition and gene expression levels for the $m$. longissimus lumborum and for SAT are shown in Table 5. In the $m$. longissimus lumborum, 16 : 1cis-9 was positively and moderately correlated $(0.7 \geq r \geq 0.3)$ with FABP4 $(P<0.01), \quad S C D \quad(P<0.01), \quad L P L$ $(P<0.05)$ and PPARG $(P<0.05)$ and was negatively correlated with PPARA $(P<0.05)$. Furthermore, 18: 1cis-9 was positively and moderately correlated with FABP4 $(P<0.01), P P A R G$ $(P<0.01), S C D(P<0.01)$ and $C P T-1 B(P<0.05)$ and was negatively correlated with FADS1 $(P<0.05)$. A moderate and positive correlation was found between 18: 1cis-11 and FABP4 and $S C D$ expression levels $(P<0 \cdot 05)$. The fatty acid $18: 2 n-6$ was negatively and moderately correlated with $C P T-1 B$ $(P<0.05)$, PPARG $(P<0.05)$ and $S C D(P<0.05)$ and was positively correlated with FADS1 $(P<0 \cdot 05)$. MUFA were positively and moderately correlated with FABP4 $(P<0 \cdot 01), P P A R G$ $(P<0.01)$, SCD $(P<0.01)$ and $C P T-1 B(P<0.05)$ and were negatively correlated with FADS1 $(P<0 \cdot 05)$. PUFA were negatively and moderately correlated with $P P A R G(P<0 \cdot 01)$ and $S C D(P<0 \cdot 01)$ and were positively associated with FADS1 $(P<0 \cdot 05)$.

In SAT, 16:0 and 18:0 fatty acid percentages were positively and moderately correlated with ACACA $(P<0.05)$, FADS2 $(P<0.05)$ and $\operatorname{GLUT4}(P<0.05)$ expression levels. Furthermore, 16:0 was positively correlated with $L P L(P<0 \cdot 01), M L X I P L$ $(P<0.01), F A S N(P<0.05)$ and PPARG $(P<0.05)$. Similar to $16: 0$, SFA was positively correlated with FADS2 $(P<0 \cdot 001)$, ACACA $(P<0.01)$, GLUT4 $(P<0.01)$, FASN $(P<0.05), \quad L P L$ $(P<0.05)$ and MLXIPL $(P<0.05)$. MUFA and 18: 1 cis-9 were negatively and moderately correlated with FADS2 $(P<0.001)$, and MUFA were also negatively correlated with FADS1 $(P<0.05)$, GLUT4 $(P<0.05)$ and LPL $(P<0.05)$. A moderate negative correlation was found between $18: 1$ cis-11 content and FADS2 $(P<0.05)$ and GLUT4 $(P<0.05)$ expression levels. A positive correlation was established between 18:1cis-11 content and CRAT $(P<0 \cdot 05)$. PUFA and $18: 2 n-6$ percentages were negatively correlated with $A C A C A(P<0.05)$ and $F A S N$ $(P<0.05)$ expression levels. 
(a)

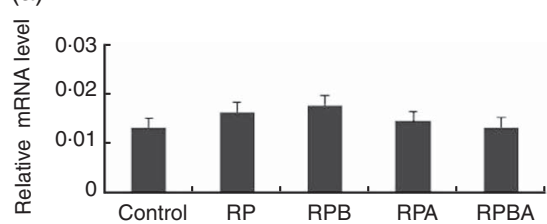

(d)

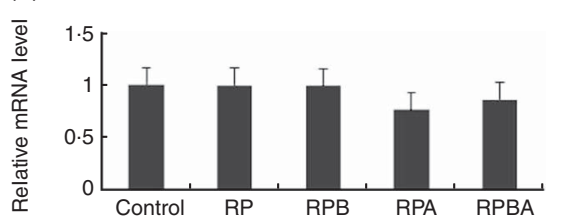

(g)

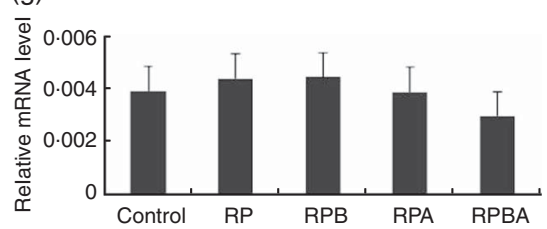

(j)

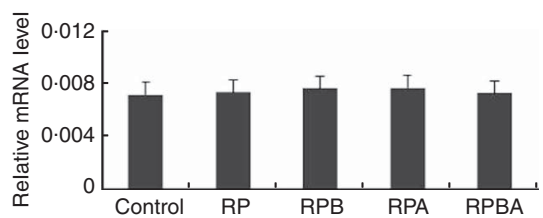

(m)

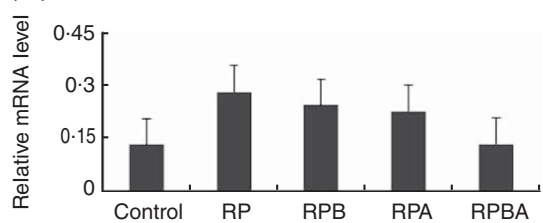

(b)

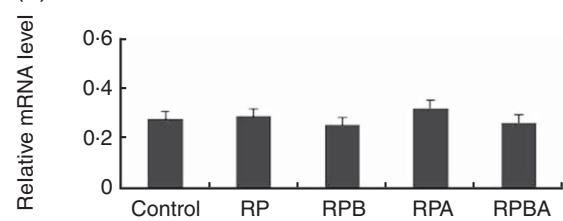

(e)

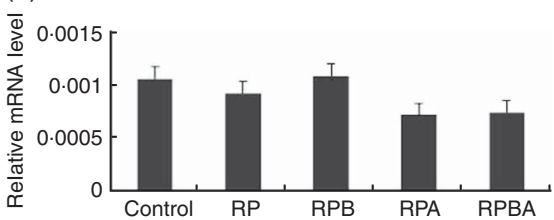

(h)

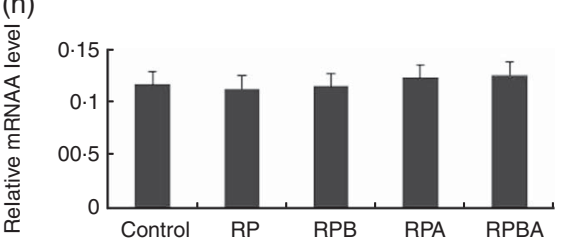

(k)

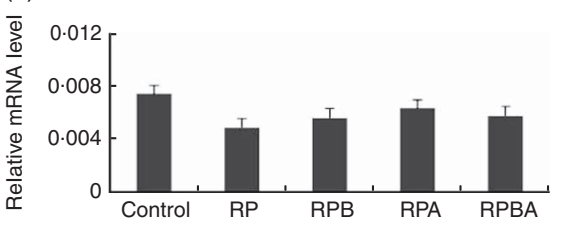

(n)

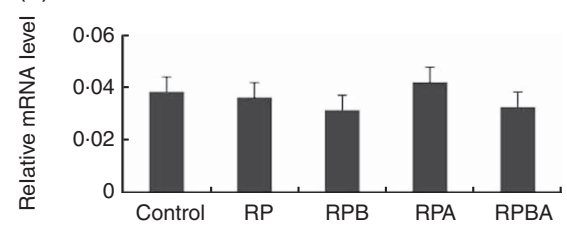

(c)

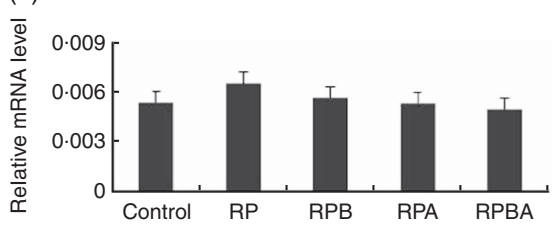

(f)

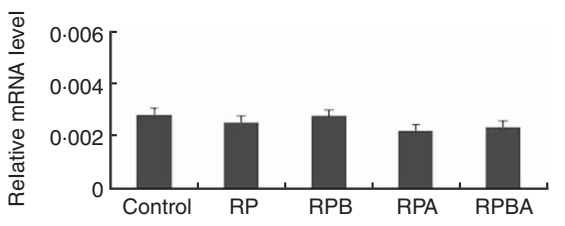

(i)

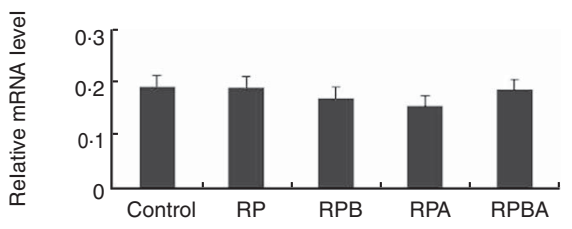

(I)

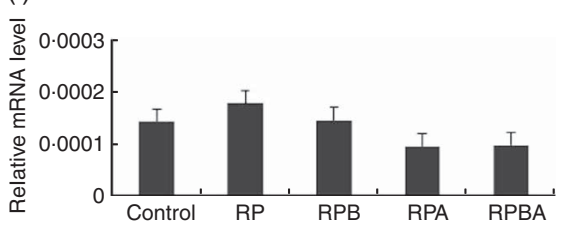

Fig. 1. Effect of dietary protein reduction, betaine and arginine on gene expression in the $m$. longissimus lumborum of pigs: (a) acetyl-CoA carboxylase; (b) carnitine O-acetyltransferase; (c) carnitine palmitoyltransferase 1; (d) fatty acid binding protein 4; (e) fatty acid desaturase 1; (f) fatty acid desaturase 2; (g) fatty acid synthase; (h) GLUT type 4; (i) lipoprotein lipase; (j) MLX interacting protein-like; (k) PPARA (protein reduction, $P=0.027$ (control diet (control) $v$. reduced protein diet (RP), reduced protein diet with betaine addition (RPB), reduced protein diet with arginine addition (RPA), reduced protein diet with betaine and arginine addition (RPBA)); (I) PPARG (arginine, $P=0.022$ (RP $v$. RPA)); betaine + arginine, $P=0.025$ (RP v. RPBA)); (m) stearoyl-CoA desaturase, (n) sterol regulatory element binding protein 1 . Values are means, with their standard errors represented by vertical bars.

\section{Discussion}

In the present study, a $19 \%$ reduction of dietary protein $(16 v$. $13 \%$ of crude protein) during the growing-finishing phase of commercial cross-bred pigs resulted in an increased IMF of $25 \%$. These results agree with previous studies, which showed that a range of dietary protein concentrations (e.g. $21 v .18 \%{ }^{(5)}, 17 v$. $15 \%{ }^{(41)}$ and $\left.16 v \cdot 13 \%^{(14)}\right)$ increases IMF content in commercial cross-bred pigs. It was previously suggested that an increase in IMF is likely due to a dietary lysine restriction, and it might be mediated by up-regulation of the lipogenic enzyme $\mathrm{SCD}^{(15)}$, which is responsible for the regulation of MUFA biosynthesis. However, the present study did not confirm the up-regulation of $S C D$ mRNA expression by RPD in pig muscle, although a significant correlation between $S C D$ expression level and MUFA proportion was observed. This is likely explained by the different pig genotypes and dietary lysine restriction percentages used in the different experiments. In fact, in the study by Madeira et al. ${ }^{(14)}$, the cross-bred pig used was $25 \%$ Duroc $\times 25 \%$ Pietrain $\times 25 \%$ Large White $\times 25 \%$ Landrace, whereas in this study the cross-bred pig used was $50 \%$ Duroc $\times 25 \%$ Large White $\times 25 \%$ Landrace. In addition, although the protein level was the same in both studies (16 v.13\%), lysine level was lower in the present study $\left(0 \cdot 8 v \cdot 0 \cdot 5^{(14)} ; 0.5 v \cdot 0 \cdot 3\right)$. In line with this, we have previously shown that the relationship between SCD protein expression and IMF content is breed specific ${ }^{(42)}$. Finally, the mRNA expression level of PPARA, a key transcription factor involved in the promotion of fatty acid oxidation ${ }^{(24)}$, decreased with dietary PR, which has not yet been previously described.

Our hypothesis was that tissue-specific responses of IMF content, fatty acid composition and backfat thickness promoted 
(a)

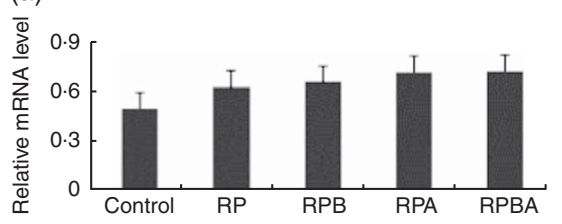

(d)

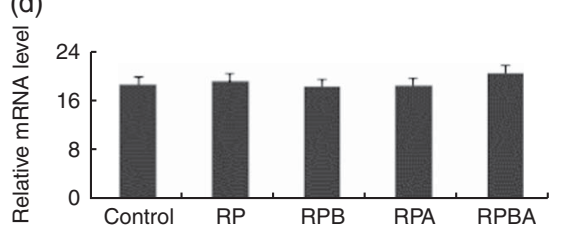

(g)

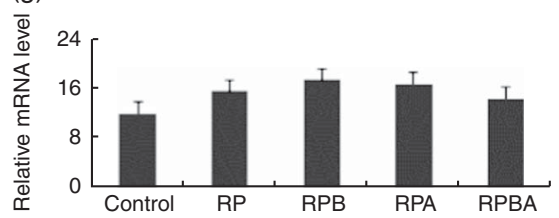

(j)

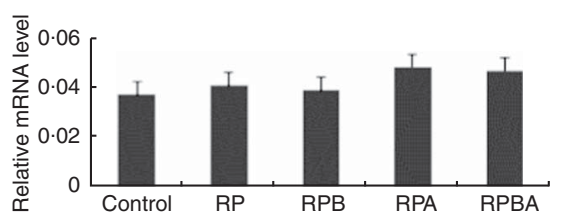

(m)

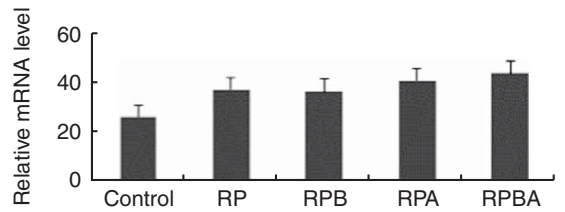

(b)

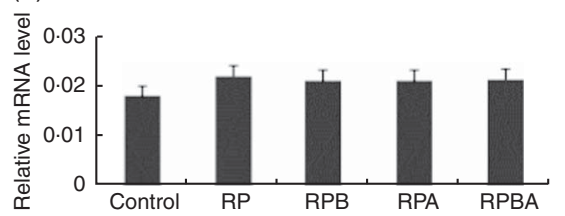

(e)

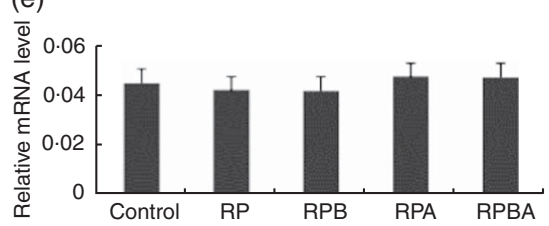

(h)

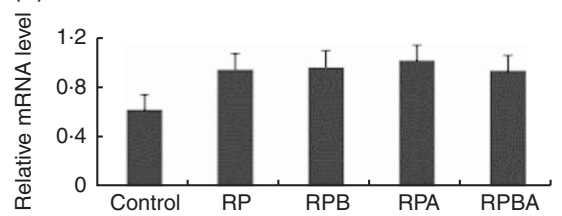

(k)

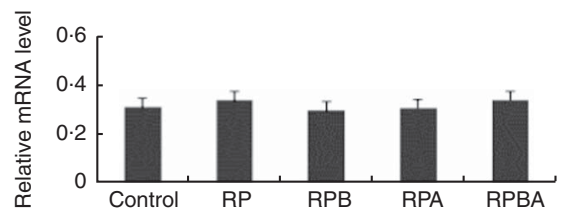

(n)

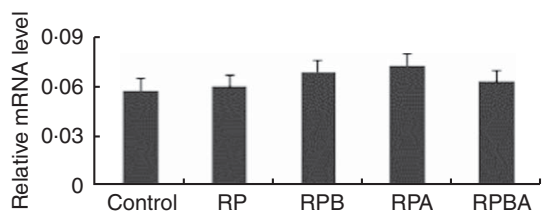

(c)

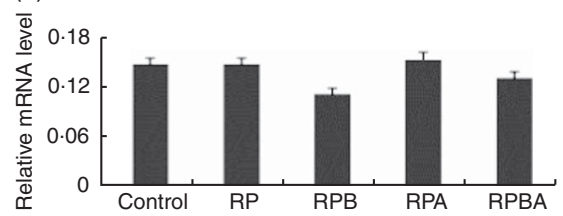

(f)

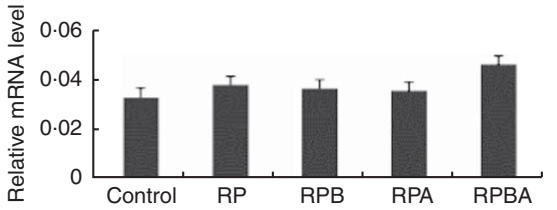

(i)

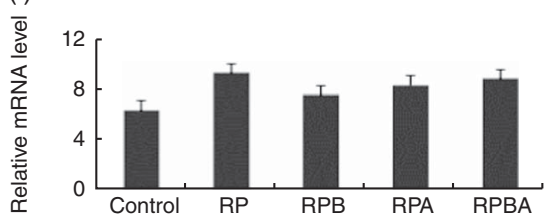

(l)

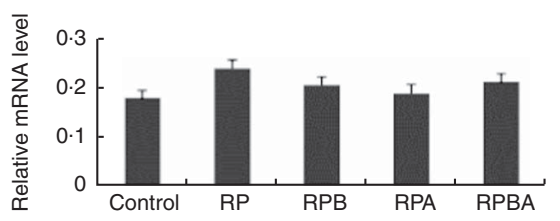

(o)

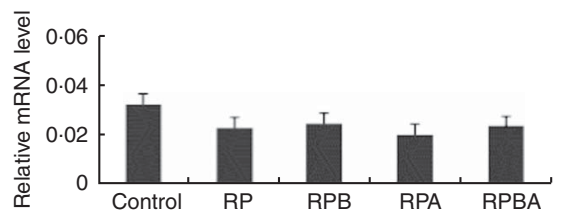

Fig. 2. Effect of dietary protein reduction, betaine and arginine on gene expression in the subcutaneous adipose tissue of pigs: (a) acetyl-CoA carboxylase; (b) CCAAT/enhancer binding protein $a$; (c) carnitine $O$-acetyltransferase (betaine, $P=0.004$ (reduced protein diet (RPD) $v$. reduced protein diet with betaine addition (RPB)); (d) fatty acid binding protein 4, (e) fatty acid desaturase 1, (f) fatty acid desaturase 2 (betaine $\times$ arginine, $P=0.028$ (reduced protein diet with betaine and arginine addition (RPBA) $v$. RPB and reduced protein diet with arginine addition (RPA)) (g) fatty acid synthase, (h) GLUT type 4 (protein reduction, $P=0.026$ (control diet (control) $v$. reduced protein diet (RP), RPB, RPA, RPBA)), (i) lipoprotein lipase (protein reduction, $P=0.015$ (control $v$. RP, RPB, RPA, RPBA)), (j) interacting protein-like, (k) PPARA, (I) PPARG (arginine, $P=0.045$ (RP v. RPA)), (m) stearoyl-CoA desaturase) (protein reduction, $P=0.023$ (control $v$. RP, RPB, RPA, RPBA)), (n) sterol regulatory element binding protein 1, (o) LPL muscle/subcutaneous adipose tissue. Values are means, with their standard errors represented by vertical bars.

by RPD in cross-bred pigs could be improved by the dietary supplementation of betaine and/or arginine. It was also our goal to elucidate the molecular mechanisms controlling lipid metabolism by these dietary supplementations in muscle and SAT. This hypothesis was based on some studies indicating that dietary betaine supplementation can increase IMF content ${ }^{(43,44)}$, decrease carcass fat deposition and increase carcass leanness in pig $^{(45,46)}$. In addition, the increase in IMF content by dietary arginine supplementation has also been previously reported ${ }^{(13,47)}$.

The results of the present study regarding the effect of RPD supplemented by betaine are in agreement with the data of Rojas-Cano et $a l^{(48)}$, who suggested that $0.5 \%$ dietary betaine supplementation of a normal protein diet does not increase IMF content in Iberian pigs from 20 to $50 \mathrm{~kg}$ of live body weight. In contrast, Feng ${ }^{(43)}$ and $\mathrm{Ma}$ et $a l^{(49)}$ reported that betaine supplementation of pig diets with $0 \cdot 10-0 \cdot 18 \%$ increases IMF content in the $m$. longissimus. Martins et al. ${ }^{(44)}$ also found that $0 \cdot 1 \%$ betaine supplementation in Alentejano pigs increases total intramuscular lipids. The explanation for this discrepancy might be the use of distinct pig genotype, age and degree of maturity, as well as different dietary protein/lysine levels (normal protein diet $v$. RPD) in the different studies. Our recent study ${ }^{(15)}$ showed that the increase in IMF content under RPD can be observed in genetically lean pigs such as cross-bred pigs with Pietrain, Large White and Landrace genetics but not in fatty breeds such as Alentejano breed.

Betaine is involved in lipid metabolism through its role in both regulation of phosphatidylcholine synthesis and fatty acid oxidation as a methyl donor during carnitine synthesis ${ }^{(50)}$. Dietary carnitine supplementation has been shown to decrease carcass fat 


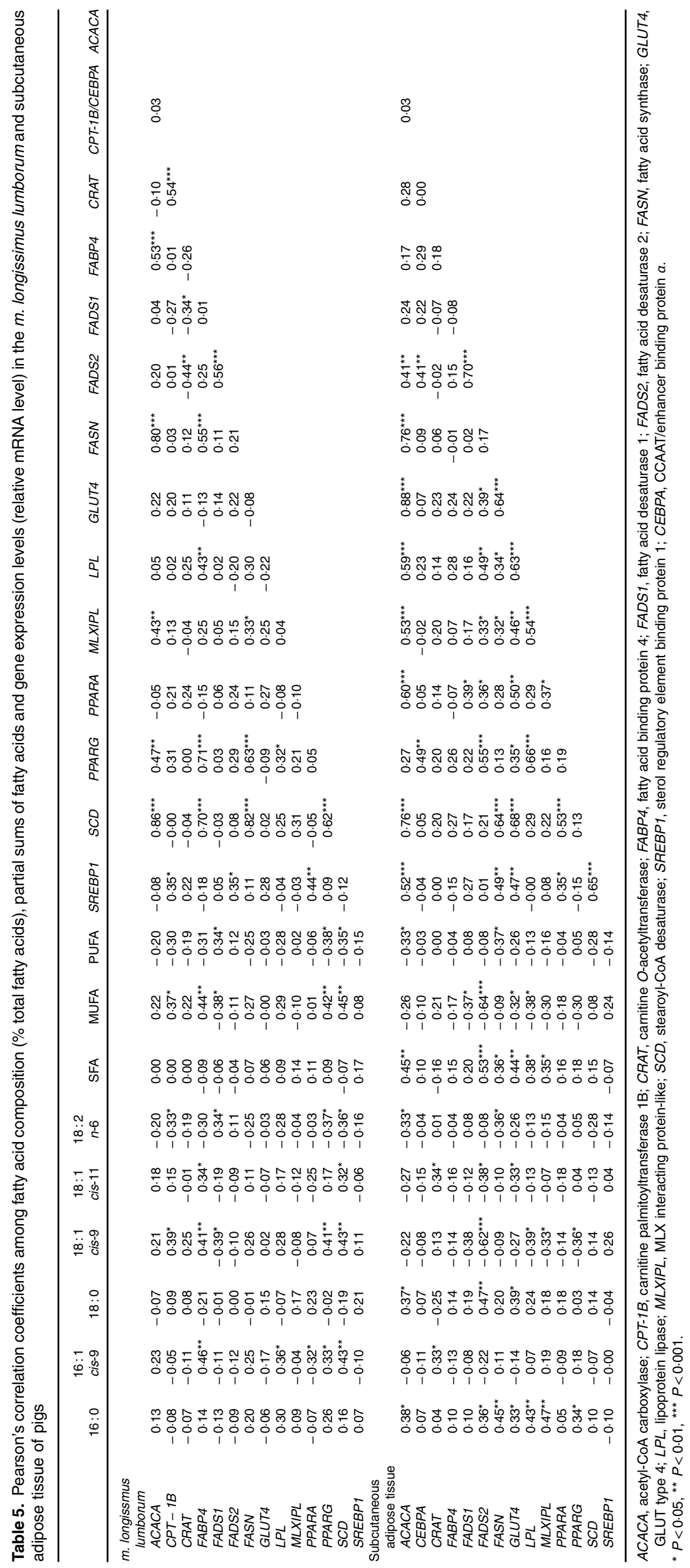


content in pigs ${ }^{(51)}$. Betaine has been reported to increase carnitine content in pig liver and muscles ${ }^{(43)}$, which indicates an effect of betaine on the reduction of carcass pig fat content in pigs. Huang et $a l^{(50)}$ reported that supplementation of pig diet with betaine leads to a decrease in the activity of CPT1 - an enzyme that plays a key role in the regulation of lipid metabolism. The present study did not find any significant effect of dietary betaine supplementation on $C P T-1 B$ gene expression. This fact can be explained by the use of distinct pig genotypes (Duroc $\times$ (Seghers $\times$ Seghers) cross-breed $v$. Duroc $\times$ Large White $\times$ Landrace cross-breed in the study by Huang et $a l .{ }^{(50)}$ and the present study, respectively). In addition, the concentrations of dietary betaine and protein levels used in this study (RPD with $13.0 \%$ of protein and $0.33 \%$ of betaine) were different from that used by Huang et al. ${ }^{(50)}$ (normal protein diet with $14.9 \%$ of protein and $0.12 \%$ of betaine).

The effect of supplementing RPD with $1.5 \%$ of arginine described in this study is in agreement with a report by Go et $a l .{ }^{(52)}$, who found that $0.82 \%$ dietary arginine supplementation does not increase IMF content in pigs. In contrast, the studies by Tan et al. ${ }^{(13)}$ and $\mathrm{Ma}$ et $a l .{ }^{(47)}$ reported an increase in IMF content in dietary trials that used 1\% dietary arginine supplementation, which is a value lower than that used in our study. The discrepancy between our findings and the report by Ma et $a{ }^{\left({ }^{(4)}\right.}$ might be explained by the use of pigs with a different genetic background (Du $\times($ Chang $\times$ Da) $)$ and distinct slaughter weights (93v.110 $\mathrm{kg}^{(47)}$, approximately). In addition, it is important to note that the feeding strategies reported in this study were based on RPD supplemented by betaine and/or arginine, whereas the studies mentioned above used betaine and arginine supplementation of diets with the recommended protein levels for those pig genetic lines. Taken together, the present study did not find any additional effect of dietary betaine and/or arginine supplementation to the increased IMF promoted by RPD in this lean commercial pig cross-breed.

The feeding strategies used in this study had a slight effect on the fatty acid compositions in muscle and SAT. The animals fed the diet supplemented with betaine had a lower percentage of beneficial MUFA in muscle, which was mainly due to a decrease in 16:1 cis-9 and 18:1 cis-11 proportions. Although SCD mRNA expression level was not affected in muscle by dietary betaine supplementation, a positive correlation was found between SCD mRNA and 16:1cis-9, 18:1cis-9, 18:1cis-11 and MUFA proportions. The increased $n-6: n-3$ PUFA ratio in SAT of betaine-supplemented pigs indicates the lower nutritional value of the fat from these animals. Our results are in agreement with those of Martins et al. ${ }^{(44)}$, who observed a slight effect of dietary betaine on fatty acid composition in the $m$. longissimus lumborum of Alentejano pig. In contrast to betaine, our study did not find any effect of dietary arginine supplementation on fatty acid composition in muscle. However, dietary supplementation with both arginine and betaine resulted in a decrease of PPARG mRNA level.

In the present study, the RPD increased the total fat content in SAT but did not affect backfat thickness. The increased fat content in SAT was accompanied by increased GLUT4, LPL and $S C D$ mRNA levels. In addition, strong significant correlations among GLUT4, LPL and SCD mRNA levels were observed. This is consistent with our previous study ${ }^{(14)}$, in which the increased total fat content in SAT was associated with the $L P L$ and $S C D$ mRNA levels promoted by the RPD.

Betaine supplementation of RPD did not affect total fat content in SAT or backfat thickness, but decreased 16:1cis-9 and $18: 1$ cis-11 proportions. In addition, a down-regulation of CRAT mRNA expression under the betaine-supplemented diet was obtained. CRAT is a rate-limiting enzyme of lipid catabolism responsible for the transport of fatty acids from the cytosol to the mitochondria for $\beta$-oxidation ${ }^{(18)}$.

The present study established that dietary arginine supplementation did not affect total fat content or fatty acid composition in SAT or backfat thickness at the $\mathrm{P}_{2}$ site. However, arginine induced the down-regulation of $P P A R G$ transcription factor in muscle and SAT. It is well known that the transcription factor $P P A R G$ is involved in fat deposition through the expression regulation of some lipogenic enzymes ${ }^{(53)}$.

In the present study, SAT had, in general, higher mRNA expression levels of genes controlling lipid metabolism when compared with the muscle. In addition, the number of correlations between major fatty acids and expression levels of key lipogenic enzymes and transcription factors was also higher in SAT than in muscle. This is likely explained by the fact that SAT is the main site for de novo fatty acid biosynthesis and lipogenesis, whereas muscles play a major role in the metabolism of glucose and degradation of lipids ${ }^{(17)}$. Therefore, SAT is more sensitive than IMF to changes in feeding strategies, mainly in those that affect lipid metabolism.

\section{Conclusions}

The present study confirms that RPD with restricted lysine levels increase IMF content and total fat content of SAT in pigs, but do not change backfat thickness at the $\mathrm{P}_{2}$ site. The increased total fat content in SAT seems to be mediated by the up-regulation of GLUT4, LPL and SCD mRNA levels. These data indicate that the supplementation of RPD with betaine and/or arginine does not affect IMF content, total fat content in SAT or backfat thickness at the $\mathrm{P}_{2}$ site. However, dietary betaine supplementation slightly affects fatty acid composition in both muscle and SAT. Betaine-supplemented diet decreased the expression of CRAT in SAT but not in muscle. Therefore, betaine might be involved in the differential regulation of some key genes of lipid metabolism in pig muscle and SAT. In spite of the lack of effect of arginine supplementation on fat content and fatty acid composition in muscle and SAT, the arginine-supplemented diet decreased the expression of PPARG transcription factor in both tissues.

Taken together, our data indicate that, under our experimental conditions, dietary betaine and/or arginine supplementation of RPD does not seem to be useful to further increase IMF content or to improve the nutritional value of meat fatty acid composition in pigs. The results of this research reinforce current evidence that adipogenesis and lipogenesis are differently regulated in pig muscle and SAT. These data contribute to understand the mechanisms of dietary regulation of fat partitioning in pigs, and therefore could help improve pig feeding strategies to address industry needs and consumer demands. 


\section{Acknowledgements}

The authors are grateful to J. Santos Silva and António Sequeira, from the Unidade de Investigação em Produção Animal (INIAV), for technical assistance.

The authors acknowledge the financial support from Fundação para a Ciência e a Tecnologia (FCT) grant (PTDC/CVT/2008/99210), CIISA project (UID/CVT/00276/2013) and individual fellowships to M. S. M. (SFRH/BPD/97432/2013). V. M. R. P. is an assistant researcher supported through an IF-FCT contract (2013 FCT investigator).

M. S. M. and J. A. M. P. performed the animal experiments. M. S. M., E. A. R., V. R. P., C. M. A. and J. A. M. P. performed the tissue sampling, laboratory work and prepared the manuscript. M. S. M., R. L., O. D., R. J. B. B. and J. A. M. P. were responsible for interpretation of the results and preparation of the manuscript. R. J. B. B. and J. A. M. P. were responsible for design of the study. All authors read and approved the findings of the study.

The authors declare that there are no conflicts of interest.

\section{References}

1. Eurostat (2015) Production of meat. http://epp.eurostat.ec. europa.eu/ (accessed March 2015).

2. Wood JD, Nute GR, Richardson RI, et al. (2004) Effects of breed, diet and muscle on fat deposition and eating quality in pigs. Meat Sci 67, 651-667.

3. De Vol DL, McKeith FK, Bechtel PJ, et al. (1988) Variations in composition and palatability traits and relationships between muscle: characteristics and palatability in a random sample of pork carcasses. J Anim Sci 66, 385-395.

4. Daszkiewicz T, Bak T \& Denaburski J (2005) Quality of pork with a different intramuscular fat (IMF) content. Pol J Food Nutr Sci 14, 31-35.

5. Doran O, Moule SK, Teye GA, et al. (2006) A reduced protein diet induces stearoyl-CoA desaturase protein expression in pig muscle but not in subcutaneous adipose tissue: relationship with intramuscular lipid formation. BrJ Nutr 95, 609-617.

6. Hyun Y, Kim JD, Ellis M, et al. (2007) Effect of dietary leucine and lysine levels on intramuscular fat content in finishing pigs. Can J Anim Sci 87, 303-306.

7. Simon J (1999) Choline, betaine and methionine interactions in chickenm pigs and fish (including crustaceans). World Poultry Sci J55, 353-374.

8. Eklund M, Bauer E, Wamatu J, et al. (2005) Potential nutritional and physiological functions of betaine in livestock. Nutr Res Rev 18, 31-48.

9. Huang QC, Xu ZR, Han XY, et al. (2008) Effect of dietary betaine supplementation on lipogenic enzyme activities and fatty acid synthase mRNA expression in finishing pigs. Anim Feed Sci Tchnol 140, 365-375.

10. Huang QC, Xu ZR, Han XY, et al. (2006) Changes in hormones, growth factor and lipid metabolism in finishing pigs fed betaine. Livest Sci 105, 78-85.

11. Jobgen WS, Fried SK, Fu WJ, et al. (2006) Regulatory role for the arginine-nitric oxide pathway in metabolism of energy substrates. J Nutr Biochem 17, 571-588.

12. Tan B, Yin Y, Liu Z, et al. (2011) Dietary L-arginine supplementation differentially regulates expression of lipid-metabolic genes in porcine adipose tissue and skeletal muscle. $J$ Nutr Biochem 22, 441-445.
13. Tan BE, Yin YL, Liu ZQ, et al. (2009) Dietary L-arginine supplementation increases muscle gain and reduced body fat mass in growing-finishing pigs. Amino Acids 37, 169-175.

14. Madeira MS, Pires VM, Alfaia CM, et al. (2014) Combined effects of dietary arginine, leucine and protein levels on fatty acid composition and gene expression in the muscle and subcutaneous adipose tissue of crossbred pigs. Br J Nutr 111, $1521-1535$.

15. Madeira MS, Pires VMR, Alfaia CM, et al. (2013) Differential effects of reduced protein diets on fatty acid composition and gene expression in muscle and subcutaneous adipose tissue of alentejana purebred and large white $\times$ landrace $\times$ pietrain crossbred pigs. BrJ Nutr 110, 216-229.

16. Dodson MV, Hausman GJ, Guan L, et al. (2010) Lipid metabolism, adipocyte depot physiology and utilization of meat animals as experimental models for metabolic research. Int J Biol Sci 6, 691-699.

17. Bergen WG \& Mersmann HJ (2005) Comparative aspects of lipid metabolism: impact on contemporary research and use of animal models. J Nutr 135, 2499-2502.

18. Zhao S, Wang J., Song X, et al. (2010) Impact of dietary protein on lipid metabolism-related gene expression in porcine adipose tissue. Nutr Metab (Lond) 7, 6.

19. Herman MA, Peroni OD, Villoria J, et al. (2012) A novel ChREBP isoform in adipose tissue regulates systemic glucose metabolism. Nature 484, 333-338.

20. Dentin R, Pégorier JP, Benhamed F, et al. (2004) Hepatic glucokinase is required for the synergistic action of ChREBP and SREBP1-1c on glycolytic and lipogenic gene expression. J Biol Chem 279, 20314-20326.

21. Liu CY, Grant AL, Kim KH, et al. (1994) Porcine somatotropin decreases acetyl-CoA carboxylase gene expression in porcine adipose tissue. Domest Anim Endocrinol 11, 125-132.

22. Clarke SD (1993) Regulation of fatty acid synthase gene expression: an approach for reducing fat accumulation. J Anim Sci 71, 1957-1965.

23. Nakamura MT \& Nara TY (2004) Structure, function, and dietary regulation of delta6, delta5, and delta9 desaturases. Annu Rev Nutr 24, 345-376.

24. Torra IP, Gervois P \& Steals B (1999) Peroxisome proliferatoractivated receptor alfa in metabolic disease, inflammation, atherosclerosis and aging. Curr Opin Lipidol 10, 151-159.

25. Hocquette JF, Graulet B \& Olivecrona T (1998) Lipoprotein lipase activity and mRNA levels in bovine tissues. Comp Biochem Physiol B Biochem Mol Biol 121, 201-212.

26. Hocquette JF, Gondret F, Baéza E, et al. (2010) Intramuscular fat content in meat-producing animals: development, genetic and nutritional control, and identification of putative markers. Animal 4, 303-319.

27. Association of Official Analytical Chemists (2000) Official Methods of Analysis, 17th ed. Arlington, VA: AOAC.

28. Clegg KM (1956) The application of the anthrone reagent to the estimation of starch in cereals. J Sci Food Agric 70, 40-44.

29. Sukhija PS \& Palmquist DL (1988) Rapid method for determination of total fatty acid content and composition of feedstuffs and feces. J Agric Food Chem 36, 1202-1206.

30. Association of Official Analytical Chemists (2005) Amino acid analysis using Zorbax Eclipse-AAA columns and the Agilent 1100 HPLC. In Official Methods of Analysis of the Association of Official Analytical Chemists International, 18th ed. p. 473 [GW Latimer and W Horwitz, editors]. Gaithersburg, MD: AOAC International.

31. Henderson JW, Ricker RD, Bidlingmeyer BA, et al. (2000) Rapid, Accurate, Sensitive and Reproducible Analysis of Amino Acids. Palo Alto, CA: Agilent Technologies (Agilent Publication No. 5980-1193EN). 
32. Folch J, Lees M \& Stanley GHS (1957) A simple method for the isolation and purification of total lipids from animal tissues. J Biol Chem 226, 497-509.

33. Carlson LA (1985) Extraction of lipids from human whole serum and lipoproteins and from rat liver tissue with methylene chloride-methanol: a comparison with extraction chloroform-methanol. Clin Chim Acta 149, 89-93.

34. Raes K, De Smet SD \& Demeyer D (2001) Effect of double-muscling in Belgian Blue young bulls on the intramuscular fatty acid composition with emphasis on conjugated linoleic acid and polyunsaturated fatty acids. Anim Sci 73, 253-260.

35. Vandesompele J, De Preter K, Pattyn F, et al. (2002) Accurate normalization of real-time quantitative RT-PCR data by geometric averaging of multiple internal control genes. Genome Biol 3, 7.

36. Andersen CL, Jensen JL \& Orntoft TF (2004) Normalization of real-time quantitative reverse transcription-PCR data: a modelbased variance estimation approach to identify genes suited for normalization, applied to bladder and colon cancer data sets. Cancer Res 64, 5245-5250.

37. Livak KJ \& Schmittgen TD (2001) Analysis of relative gene expression data using real-time quantitative PCR and the 2(-Delta C(T)) method. Methods 25, 402-408.

38. Fleige S, Walf V, Huch S, et al. (2006) Comparison of relative mRNA quantification models and the impact of RNA integrity in quantitative real-time RT-PCR. Biotechnol Lett 28, 1601-1613.

39. SAS Institute Inc. (2009) SAS/STAT 9.2 User's Guide, 2nd ed. Cary, NC: SAS Institute Inc.

40. Madeira MS, Alfaia CM, Costa P, et al. (2015) Effect of betaine and arginine in lysine-deficient diets on growth, carcass traits, and pork quality. J Anim Sci 93, 4721-4733.

41. Alonso V, Campo MDM, Provincal L, et al. (2010) Effect of protein level in commercial diets on pork meat quality. Meat Sci 85, 7-14.

42. Bessa RJB, Hughes RA, Jeronimo E, et al. (2013) Effect of pig breed and dietary protein level on selected fatty acids and stearoyl-coenzyme A desaturase protein expression in longissimus muscle and subcutaneous fat. J Anim Sci $\mathbf{9 1}$, $4540-4546$
43. Feng J (1996) Effects of betaine on growth performance, carcass characteristics and meat quality and approach to mechanism of the effects in finishing swine. Master Thesis, Zhejiang Agriculture University, Hangzhou.

44. Martins JM, Neves JA, Freitas A, et al. (2012) Effect of longterm betaine supplementation on chemical and physical characteristics of three muscles from the Alentejano pig. J Sci Food Agric 92, 2122-2127.

45. Matthews JO, Southern LL, Higbie AD, et al. (2001) Effects of betaine on growth, carcass characteristics, pork quality, and plasma metabolites of finishing pigs. J Anim Sci $\mathbf{7 9}$, $722-728$.

46. Yan XC (2001) Effects of betaine on growth hormone releasing factor (GRF) and approach to the mechanism in the hypothalamus of finishing pig. MD Dissertation, Zhejiang University, Hangzhou.

47. Ma X, Lin Y, Jiang Z, et al. (2010) Dietary arginine supplementation enchances antioxidative capacity and improves meat quality of finishing pigs. Amino Acids 38, 95-102.

48. Rojas-Cano ML, Lara L, Lachica M, et al. (2011) Influence of betaine and conjugated linoleic acid on development of carcass cuts of Iberian pigs growing form 20 to $50 \mathrm{~kg}$ body weight. Meat Sci $\mathbf{8 8}, 525-530$.

49. Ma YL, Wang L, Yong JH, et al. (2000) Effects of betaine on carcass composition and meat quality I finishing pigs. J Ningxia Univ (Natural Science Edition) 21, 349-351.

50. Huang QC, Han XY, Xu ZR, et al. (2009) Betaine suppresses carnitine palmitoyltransferase I in skeletal muscle but not in liver of finishing pigs. Lives Sci 126, 130-135.

51. Owen KQ, Nelssen JL, Goodband RD, et al. (1996) Effect of L-carnitine and soybean oil on growth performance and body composition of early-weaned pigs. J Anim Sci 74, 1612-1619.

52. Go G, Wu G, Silvey DT, et al. (2012) Lipid metabolism in pigs fed supplemented conjugated linoleic acid and/or dietary arginine. Amino Acids 43, 1713-1726.

53. Guo X, Tang R, Wang W, et al. (2011) Effects of dietary protein/carbohydrate ratio on fat deposition and gene expression of peroxisome proliferator activated receptor $\gamma$ and heart fatty acid-binding protein of finishing pigs. Lives Sci 140, 111-116. 